\title{
FONTES E DOSES DE NITROGÊNIO NA ADUBAÇÃO QUIMICA DO CAFEEIRO EM LATOSSOLO ROXO E PODZÓLICO VERMELHO-AMARELO ORTO ${ }^{\left({ }^{1}\right)}$
}

\author{
FERDINANDO ROBERTO PUPO DE MORAES $\left({ }^{2}\right)$, WALTER LAZZARINI $\left({ }^{2}\right)$, \\ GENESIO DA SILVA CERVELLINI $\left({ }^{2,6}\right)$, SERGIO VASCO DE TOLEDO $\left({ }^{2}\right)$, \\ MÁRIO VIEIRA DE MORAES $\left({ }^{2}\right)$, ANTONIO JUNQUEIRA REIS $\left({ }^{3}\right)$, \\ TÜLIO RIBEIRO ROCHA $\left({ }^{4}\right)$ e ARMANDO CONAGIN $\left({ }^{5}\right)$
}

\begin{abstract}
RESUMO
Uréia, sulfato de amônio, salitre-do-chile e Nitrocalcio, nas doses de 75 , 150,225 e $300 \mathrm{~kg}$ de nitrogenio por hectare, foram aplicados em experimentos com café Mundo-Novo, instalados em Latossolo Roxo da região de Ribeirão Preto e em Podzólico Vermelho-Amarelo orto da regiāo de Mococa (SP). As produçðes foram crescentes com os aumentos de nitrogenio aplicado, sendo que as respostas para suas maiores quantidades foram maiores no Podzólico Vermelho-Amarelo orto. $\mathrm{O}$ sulfato de amónio, o Nitrocálcio e a uréia mostraram-se superiores ao salitre-do-chile no Podzólico Vermelho-Amarelo orto, apesar de a urếa não apresentar diferenças significativas relativamente ao slitre-do-chile. Em Latossolo Roxo, conquanto houvesse a mesma tendência, as diferenças ñ̄o foram significativas. $O$ parcelamento das doses de nitrogênio não beneficiou a produção no Latossolo Roxo, porém as produçðes correspondentes ao parcelamento em quatro vezes foram maiores no Podzólico Vermelho-A marelo orto.

Termos de indexação: cafeeiro; adubação; fertilizantes; nitrogênio (N); uréia; sulfato de amônio; salitre-do-chile; Nitrocálcio; doses; fracionamento e parcelamento.

(1) Parcialmente subvencionado pelo Instituto Brasileiro đo Café. Recebido para publicação em 4

$\left({ }^{2}\right)$ Seção de Café, Instituto Agronômico (IAC), Caixa Postal 28, 13100 - Campinas (SP).

$\left({ }^{3}\right)$ Estação Experimental de Ribeirão Preto, IAC.

(4) Estação Experimental de Mococa, IAC.

$\left({ }^{5}\right)$ Divisão de Plantas Alimentícias Básicas, IAC.

${ }^{6}$ ) Com bolsa de suplementação do CNPq.
\end{abstract} de agosto de 1983. 


\section{INTRODUÇÃO}

Pertencem estes ensaios a uma série histórica de experimentos realizados a partir de 1955 pela Seção de Café do IAC e que vieram concretizar conceitos novos sobre a utilização de adubos químicos para a cultura do cafeeiro.

Até então, o uso de esterco de cocheira ou outro adubo orgânico equivalente, além de pequenas quantỉdades de fertilizantes químicos, era a adubação básica geralmente preconizada, aplicada uma vez por ano em sulcos ou covas, com distribuição do fertilizante nitrogenado em cobertura. A Seção de Café, a partir de 1955 , estabeleceu as proporçðes de $200 \mathrm{~g}$ de N, $100 \mathrm{~g}$ de $\mathrm{P}_{2} \mathrm{O}_{s}$ e $200 \mathrm{~g}$ de $\mathrm{K}_{2}, \mathrm{O}$ para adubação de cafeeiros com produção estimada de 100 sacos de café em coco por 1.000 pés, recomendando aplicação parcelada, várias vezes por ano e em cobertura (LAZZARINI et alii, 1967). Em abril de 1958, expediu comunicado a respeito da adubação química, derrogando o conceito de essencialidade da adubação orgânica para o cafeeiro: considerando a adubação mineral como básica, podendo ser completada com a orgânica, e que poderia ser mantida uma lavoura altamente produtiva com o emprego de adubos minerais. Esse conceito possibilitou a renovação da lavoura cafeeira, liberando-a da sujeição aos adubos orgânicos, tidos até então como essenciais.

Já em 1956, sabia-se que para a maioria dos solos cultivados com café no Estado de São Paulo, o nitrogênio era o nutriente que com maior freqüencia e intensidade reagia sobre o desenvolvimento e produção dessa cultura (LAZZARINI et alii, 1967). Também já era conhecida a grande mobilidade deste nutriente no solo e a necessidade de seu constante suprimento durante a formação dos ramos e frutos.

Nesse mesmo ano, foi instalado em Campinas o primeiro ensaio de fontes, doses e fracionamento do nitrogênio na adubação química do cafeeiro (LAZZARINI et alii, 1967; MORAES et alii, 1976). Repetiçסes do ensaio foram instaladas em Pindorama, Ribeirão Preto e Mococa (LAZZARINI et alii, 1967). O de Pindorama, iniciado em 1958, apresentou deficiências de boro e zinco generalizadas e provavelmente enxofre, tendo sido encerrado em 1963, servindo para outros estudos de correção de deficiências. Os ensaios de Ribeirão Preto e Mococa são apresentados no presente trabalho.

O nitrogênio, juntamente com o potássio, foram os macronutrientes que se mostraram capazes de aumentar a produção do cafeeiro em ensaio realizado por MALAVOLTA et alii (1958), que observaram também a necessidade de ambos os nutrientes conjuntamente para elevação da produção. 
CATANI \& MORAES (1958) verificaram também serem o nitrogênio e o potássio os macronutrientes absorvidos em maiores quantidades. LOTT et alii (1961) e GALLO et alii (1967, 1970) mostraram ser o nitrogênio o macronutriente mais carente nos cafezais paulistas.

GALLO et alii (1971) encontraram, através da análise foliar dos cafeeiros em ensaio de fontes, doses e fracionamento do nitrogênio instalado em Campinas, que os teores de nitrogênio total ou nitrogênio nítrico determinados em janeiro crescem linearmente com as quantidades de nitrogênio aplicadas, não havendo, porém, correlação entre produção obtida e fracionamento das doses de nitrogênio aplicadas. $O$ mesmo foi verificado por HIROCE et alii (1974), em estudo semelhante realizado em ensaio instalado em Mococa, quando os coeficientes de correlação entre os teores de nitrogênio nítrico nas folhas e produçðes foram respectivamente $0,97 \mathrm{e}$ 0,89 , com elevada significação estatística.

MORAES et alii (1976) verificaram que houve um efeito linear e positivo para as quantidades de nitrogênio aplicadas, não havendo, porém, diferenças de produçðes com a utilização de fracionamentos dessas doses.

MORAES et alii (1979) e HIROCE et alii (1977), analisando o solo das parcelas dos ensaios semelhantes instalados em Campinas e Mococa, verificaram que o sulfato de amônio provocou maior acidez do solo e o salitre-do-chile a diminuiu, fato já observado por ABRUÑA \& VICENTE-CHANDLER (1963) e MORAES et alii (1976).

\section{MATERIAL E MÉTODOS}

Foram instalados em Latossolo Roxo da Estação Experimental de Ribeirão Preto e em Podzólico Vermelho-Amarelo orto da Estação Experimental de Mococa experimentos idênticos, com sorteios diferentes para as parcelas, seguindo o delineamento de fatorial $4^{3}$ inteiramente casualizado, sem repetiçðes, para estudo de quatro fertilizantes químicos nitrogenados aplicados em quatro doses e em quatro esquemas de fracionamento, utilizando-se plantas do cultivar Mundo Novo. A parcela experimental era constituída por quatro linhas de quatro covas plantadas no espaçamento de $3 \times 2 \mathrm{~m}$, sendo consideradas úteis as quatro covas centrais. Cada cova recebeu quatro plantas eqüidistantes do centro e espaçadas de $25 \mathrm{~cm}$.

Os quatro fertilizantes nitrogenados foram a uréia, com $45 \%$ de nitrogênio, o sulfato de amônio, com $20 \%$ de nitrogênio, o salitre-do-chile, com $15,5 \%$ de nitrogênio, e o Nitrocálcio, com 20,5\% de nitrogênio até 1968 e $27 \%$ de nitrogênio após 1968 , aplicados em quantidades correspondentes a 
$75,150,225$ e $300 \mathrm{~kg}$ de nitrogênio por hectare e por ano, e obedecendo aos seguintes esquemas de fracionamentos:

duas vezes, em outubro e fevereiro;

quatro vezes, em outubro, dezembro, fevereiro e abril; cinco vezes, em outubro, dezembro, fevereiro, abril e julho;

nove vezes, em todos os meses de outubro a maio e mais uma aplicação em julho.

A partir de 1964, em conseqüência da pequena reação observada, os esquemas de fracionamento passaram a ser:

uma vez, em dezembro;

duas vezes, em outubro e fevereiro;

três vezes, em outubro, fevereiro e abril;

quatro vezes, ẹm outubro, dezembro, fevereiro e abril.

Nas parcelas em que os fertilizantes nitrogenados seriam aplicados no menor número de fracionamento da maior dose, ou seja, a dose 4, aplicada duas vezes por ano até 1963 e uma só vez a partir de 1964, o tratamento foi suspenso, transformando-se no nível zero de nitrogênio, conservando-se as adubaçбes básicas com fósforo e potássio. Por isso, foram realizadas duas análises estatísticas: uma para três doses e quatro parcelamentos, a qual chamaremos raiz quadrada do desvio-padrão $\sqrt{\mathrm{S}}=\mathrm{S}_{1}$, e outra com quatro doses e três parcelamentos, $\sqrt{\mathrm{S}}=\mathrm{S}_{2}$, do mesmo modo coeficiente de variação $\mathrm{CV}_{1}$ e $\mathrm{CV}_{2}$. Os dados de produçðes de café foram obtidos das colheitas das plantas úteis de cada parcela. $O$ rendimento em café beneficiado foi calculado a partir das amostras do café colhido de cada parcela, secas e processadas separadamente,

Na Estação Experimental de Ribeirão Preto, o ensaio foi instalado em dezembro de 1957, e os cafeeiros receberam a seguinte adubação: antes do plantio, as covas foram adubadas com $120 \mathrm{~g}$ de $\mathrm{P}_{2} \mathrm{O}_{5}$ como superfosfato triplo e $15 \mathrm{~g}$ de $\mathrm{K}_{2} \mathrm{O}$ como cloreto de potássio. Em setembro de 1958, foram aplicados $8 \mathrm{~g}$ de $\mathrm{P}_{2} \mathrm{O}_{5}$ como superfosfato simples por planta e, a partir do ano agrícola 1960/61, a adubação básica passou a ser $40 \mathrm{~g}$ de $\mathrm{P}_{2} \mathrm{O}_{5}$ e $90 \mathrm{~g}$ de $\mathrm{K}_{2} \mathrm{O}$ por planta por ano.

Adubação nitrogenada - Após o pegamento, as mudas receberam cerca de $11 \mathrm{~g}$ dos adubos nitrogenados aplicados até abril de 1958. Em $1958 / 59$, todos os tratamentos receberam apenas a dose 1 de nitrogênio aplicada em quatro parcelamentos. Em 1959/60-1961/62 as plantas receberam as doses 1 e 2 parceladas em quatro vezes, sendo que a 2 também substituiu as doses 3 e 4 . A partir de 1963/64, quando se deu a quarta colheita, os adubos nitrogenados foram aplicados de acordo com o plano experimental para doses e parcelamentos. 
Modo de adubar - O fósforo e o potássio foram aplicados uma única vez, nos meses de setembro, ligeiramente enterrados, em pequenos sulcos abertos no limite da projeção da copa dos cafeeiros, e o nitrogênio em cobertura. Foram anotados os dados de colheitas de 1960 a 1969.

No ensaio da Estação Experimental de Mococa, instalado em março de 1960, empregaram-se as seguintes doses de fósforo e potássio: $60 \mathrm{~g}$ de $\mathrm{P}_{2} \mathrm{O}_{5}$ nas covas de plantio e iguais quantidades anuais por planta a partir do ano agrícola $1962 / 63$, na forma de superfosfato simples; $15 \mathrm{~g}$ de $\mathrm{K}_{2} \mathrm{O}$ nas covas de plantio, $15 \mathrm{~g}$ de $\mathrm{K}_{2} \mathrm{O}$ em 1960/61, 30g de $\mathrm{K}_{2} \mathrm{O}$ em 1961/62,60g de $\mathrm{K}_{2} \mathrm{O}$ em $1962 / 63$ e $180 \mathrm{~g}$ de $\mathrm{K}_{2} \mathrm{O}$ por planta a partir do ano agrícola 1963 / 64 , sempre na forma de cloreto de potássio.

As adubações nitrogenadas foram feitas com os quatro adubos nitrogenados em estudo, utilizando-se as seguintes quantidades de nitrogênio: $11 \mathrm{~g}$ por planta até abril de 1960 e doses 1 e 2 de $\mathrm{N}$ subdivididas em quatro parcelas em 1960/61 e 1961/62. A partir do ano agrícola 1962/63, passaram a funcionar os esquemas de dose e fracionamento planejados para o ensaio. A mistura de fósforo e potássio foi aplicada ligeiramente enterrada no limite de projeção da copa dos cafeeiros e, o nitrogênio, em cobertura. Foram coletados os dados de colheita de 1962 a 1971.

A análise estatística para fontes e doses foi realizada com os dados obtidos com as quatro doses e os parcelamentos 2,3 e 4 com desvio-padrão designado $S_{1}$, enquanto, para os parcelamentos utilizados, os dados obtidos com as doses 1,2 e 3 e, os quatro parcelamentos, com desvio-padrão designado $S_{2}$.

\section{RESULTADOS E DISCUSSAO}

\subsection{Ribeirão Preto}

As produçôes de cafeeiros são de ciclos bianuais, alternando-se produçðes altas e baixas e, para evitar a variabilidade maior nos anos de baixa produção, apresentadas como exemplo no quadro 1 , os estudos estatísticos são baseados em períodos de número par de produçôes.

Os quadros 2, 3 e 4 apresentam a média das produçбes obtidas por fontes, doses e parcelamentos de nitrogênio no primeiro quadriênio, 1960-63, nos biênios 1964-65, 1966-67 e 1968-69; e no período 1964-69, compreendendo os três biênios citados. O quadro 5 apresenta a média das produçð̃es obtidas por doses, fracionamento e fontes de nitrogênio no período 196469. 
QUADRO 1 - Média geral de produção de café beneficiado e coeficientes de variação obtidos em Ribeirão Preto e Mococa

\begin{tabular}{|c|c|c|c|c|}
\hline \multirow{3}{*}{ Ano } & \multicolumn{4}{|c|}{ Localidade } \\
\hline & \multicolumn{2}{|c|}{ Mococa } & \multicolumn{2}{|c|}{ Ribeirão Preto } \\
\hline & $\begin{array}{l}\text { Média de } \\
\text { produção }\end{array}$ & $\mathrm{CV}$ & $\begin{array}{l}\text { Média de } \\
\text { produção }\end{array}$ & $\mathrm{CV}$ \\
\hline & $\mathrm{kg} /$ planta & $\%$ & $\mathrm{~kg} /$ planta & $\%$ \\
\hline 1964 & - & - & 0,012 & 58 \\
\hline 1965 & 0,567 & 35 & 1,218 & 26 \\
\hline 1966 & 1,341 & 23 & 0,270 & 80 \\
\hline 1967 & 0,144 & 57 & 0,528 & 32 \\
\hline 1968 & 0,944 & 31 & 0,720 & 33 \\
\hline 1969 & 0,154 & 43 & 0,288 & 38 \\
\hline 1970 & 0,868 & 28 & - & - \\
\hline \multicolumn{5}{|l|}{ Quadriênio } \\
\hline $1966 / 69$ & 0,642 & 22 & 0,450 & 30 \\
\hline
\end{tabular}

QUADRO 2 - Fontes de nitrogênio na adubação do cafeeiro: média da produção acumulada de café beneficiado em Latossolo Roxo. Cada dado é média dos tratamentos com as quatro doses e os parcelamentos 2,3 e 4, acumulados durante os perfodos indicados

\begin{tabular}{|c|c|c|c|c|c|c|}
\hline \multirow{2}{*}{ Perrodo } & \multicolumn{4}{|c|}{ Fontes de $\mathrm{N}$} & \multirow{2}{*}{$\mathrm{CV}$} & \multirow{2}{*}{$\mathbf{F}$} \\
\hline & Uréia & $\begin{array}{l}\text { Sulfato de } \\
\text { amônio }\end{array}$ & $\begin{array}{l}\text { Salitre-do- } \\
\text {-chile }\end{array}$ & $\begin{array}{l}\text { Nitro- } \\
\text { cálcio }\end{array}$ & & \\
\hline & \multicolumn{4}{|c|}{ - $\mathrm{kg} /$ planta } & $\%$ & \\
\hline $1960-63$ & 0,746 & 0,790 & 0,502 & 0,724 & 19 & $11,36 *$ \\
\hline $1964-65$ & 0,702 & 0,700 & 0,603 & 0,664 & 28 & $0,73 \mathrm{~ns}$ \\
\hline $1966-67$ & 0,403 & 0,481 & 0,373 & 0,418 & 40 & $0,90 \mathrm{~ns}$ \\
\hline $1968-69$ & 0,513 & 0,553 & 0,429 & 0,511 & 21 & $2,11 \mathrm{~ns}$ \\
\hline $1964-69$ & 0,539 & 0,576 & 0,468 & 0,531 & 24 & $1,46 \mathrm{~ns}$ \\
\hline
\end{tabular}

*: Significativo a 5\% de probabilidade; ns: Não significativo. 
QUADRO 3 - Doses de nitrogênio na adubação do cafeeiro: média da produção acumulada de café beneficiado em Latossolo Roxo. Cada dado é média dos tratamentos com as quatro fontes e os parcelamentos 2,3 e 4 , acumulados durante os períodos indicados

\begin{tabular}{|c|c|c|c|c|c|c|c|}
\hline \multirow{2}{*}{ Periodo } & \multicolumn{5}{|c|}{ Doses de $N(\mathrm{~kg} / \mathrm{ha})$} & \multirow{2}{*}{$\mathrm{CV}$} & \multirow{2}{*}{ F } \\
\hline & 0 & 75 & 150 & 225 & 300 & & \\
\hline & \multicolumn{5}{|c|}{$-\mathrm{kg} /$ planta } & $\%$ & \\
\hline $\begin{array}{l}1964-65 \\
1966-67 \\
1968-69 \\
1964-69\end{array}$ & $\begin{array}{l}0,396 \\
0,197 \\
0,316 \\
0,303\end{array}$ & $\begin{array}{l}0,531 \\
0,379 \\
0,394 \\
0,436\end{array}$ & $\begin{array}{l}0,622 \\
0,373 \\
0,501 \\
0,486\end{array}$ & $\begin{array}{l}0,725 \\
0,460 \\
0,557 \\
0,595\end{array}$ & $\begin{array}{l}0,791 \\
0,463 \\
0,554 \\
0,603\end{array}$ & $\begin{array}{l}28 \\
40 \\
21 \\
24\end{array}$ & $\begin{array}{l}4,44^{*} \\
1,07 n \\
4,50^{*} \\
4,45^{*}\end{array}$ \\
\hline
\end{tabular}

* Significativo a 5\% de probabilida de; ns: Não significativo.

QUADRO 4 - Parcelamento e doses de nitrogênio na adubação do cafeeiro: média da produçáo acumulada de café beneficiado em Podzólico Vermelho-Amarelo orto. Cada dado é média dos tratamentos com as doses 1,2 e $3 \mathrm{e}$ as quatro fontes, acumuladas durante os períodos indicados

\begin{tabular}{|c|c|c|c|c|c|c|}
\hline \multirow{2}{*}{ Perfodo } & \multicolumn{4}{|c|}{ Parcelamento } & \multirow{2}{*}{$\mathrm{CV}$} & \multirow{2}{*}{$F$} \\
\hline & 1 & 2 & 3 & 4 & & \\
\hline & \multicolumn{4}{|c|}{$-\mathrm{kg} / \mathrm{planta}$} & $\%$ & \\
\hline $1964-65$ & 0,608 & 0,615 & 0,618 & 0,646 & 24 & $0,16 \mathrm{~ns}$ \\
\hline $1966-67$ & 0,324 & 0,416 & 0,457 & 0,359 & 48 & $0,93 \mathrm{~ns}$ \\
\hline $1968-69$ & 0,443 & 0,487 & 0,503 & 0,462 & 29 & $0,44 \mathrm{~ns}$ \\
\hline $1964-69$ & 0,458 & 0,506 & 0,579 & 0,487 & 27 & $0,48 \mathrm{~ns}$ \\
\hline
\end{tabular}

ns: Não significativo.

Devido à aplicação apenas das doses 1 e 2 de nitrogênio até o ano agrícola 1961-1962, as produçðes do quadriênio 1960-63 só mostraram di- 
ferenças para as quatro diferentes fontes, sendo significativas de acordo com o teste -de Tukey 5\% as diferenças entre o salitre-do-chile e demais fontes, que apresentaram produçðes $50 \%$ maiores.

No biênio 1964-65, somente as quantidades de nitrogênio aplicadas mostraram efeitos significativos segundo o teste $\mathrm{F}$ a $5 \%$, com aumentos de produção correspondentes às doses aplicadas.

No biênio 1966-67 o coeficiente de variação foi muito elevado, sendo impossível detectar diferenças de quantidades ou fontes de nitrogênio aplicadas.

QUADRO 5 - Doses, parcelamento e fontes do nitrogênio na adubação do cafeeiro: média da produção acumulada de café beneficiado no período 1964-69, em Latossolo Roxo

\begin{tabular}{|c|c|c|c|c|c|}
\hline \multirow{2}{*}{$\begin{array}{c}\text { Doses de } \\
\mathbf{N}\end{array}$} & \multirow{2}{*}{$\begin{array}{l}\text { Parcela- } \\
\text { mento }\end{array}$} & \multicolumn{4}{|c|}{ Fontes de $\mathrm{N}$} \\
\hline & & Uréia & $\begin{array}{l}\text { Sulfato de } \\
\text { amônio }\end{array}$ & $\begin{array}{l}\text { Salitre-do- } \\
\text {-chile }\end{array}$ & $\begin{array}{l}\text { Nitro- } \\
\text { cálcio }\end{array}$ \\
\hline \multicolumn{2}{|l|}{$\mathrm{kg} / \mathrm{ha}$} & \multicolumn{4}{|c|}{ - $\mathrm{kg} /$ planta } \\
\hline 75 & 1 & 0,546 & 0,507 & 0,183 & 0,554 \\
\hline 75 & 2 & 0,366 & 0,572 & 0,414 & 0,376 \\
\hline 75 & 3 & 0,393 & 0,348 & 0,587 & 0,407 \\
\hline 75 & 4 & 0,323 & 0,341 & 0,354 & 0,731 \\
\hline 150 & 1 & 0,449 & 0,450 & 0,360 & 0,540 \\
\hline 150 & 2 & 0,586 & 0,646 & 0,342 & 0,556 \\
\hline 150 & 3 & 0,455 & 0,548 & 0,462 & 0,605 \\
\hline 150 & 4 & 0,417 & 0,632 & 0,367 & 0,367 \\
\hline 225 & 1 & 0,615 & 0,438 & 0,247 & 0,612 \\
\hline 225 & 2 & 0,798 & 0,583 & 0,454 & 0,377 \\
\hline 225 & 3 & 0,551 & 0,526 & 0,484 & 0,863 \\
\hline 225 & 4 & 0,636 & 0,578 & 0,644 & 0,475 \\
\hline 300 & 2 & 0,732 & 0,764 & 0,471 & 0,414 \\
\hline 300 & 3 & 0,744 & 0,642 & 0,471 & 0,614 \\
\hline 300 & 4 & 0,470 & 0,732 & 0,589 & 0,590 \\
\hline \multicolumn{2}{|c|}{ Sem nitrogênio (média) } & 0,301 & 0,301 & 0,301 & 0,301 \\
\hline
\end{tabular}

$\mathrm{CV}_{1}=24 \% . \mathrm{CV}_{2}=27 \% . \mathrm{S}_{1}=0,12843 . \mathrm{S}_{2}=0,13213$. 
No biênio $1968-69$, somente as quantidades de nitrogênio aplicadas mostraram efeito significativo pelo teste $\mathrm{F}$ a $5 \%$, com aumentos de produção até quantidade de $225 \mathrm{~kg}$ de nitrogênio por hectare, não havendo diferenças de prođução correspondentes à aplicação de $300 \mathrm{~kg}$ de nitrogênio por hectare.

As análises do período 1964-69 mostraram apenas um efeito significativo segundo o teste $\mathrm{F}$ a $5 \%$ para as quantidades crescentes de nitrogênio aplicado, não havendo diferenças significativas para suas fontes.

O fracionamento das quantidades de nitrogênio não mostrou nenhum efeito durante o período 1964-69. Resultados similares foram obtidos por GALLO et alii (1971) e MORAES et alii (1976), em Campinas, e por HIROCE et alii (1974) em Mococa. Nos dois locais, as produçoes nao correspondem às pequenas diferenças observadas para a concentração de nitrogênio nítrico ou total quando a aplicação foi realizada de uma só vez, razão pela qual se deve considerar com cuidado as recomendaçðes de fracionamento do nitrogênio.

\subsection{Mococa}

O quadro 6 apresenta as médias das produçðes por fontes de nitro-

QUADRO 6 - Fontes de nitrogênio na adubaçăo do cafeeiro: média da produção acumulada de café beneficiado em Podzólico Vermelho-Amarelo orto. Cada dado é média dos tratamentos com as quatro doses e os parcelamentos 2,3 e 4 acumulados durante os períodos indicados

\begin{tabular}{|c|c|c|c|c|c|c|}
\hline \multirow{2}{*}{ Perfodo } & \multicolumn{4}{|c|}{ Fontes de $\mathrm{N}$} & \multirow{2}{*}{$\mathrm{CV}$} & \multirow{2}{*}{$F$} \\
\hline & Uréia & $\begin{array}{l}\text { Sulfato de } \\
\text { amonio }\end{array}$ & $\begin{array}{l}\text { Salitre-do- } \\
\text {-chile }\end{array}$ & $\begin{array}{l}\text { Nitro- } \\
\text { cálcio }\end{array}$ & & \\
\hline & \multicolumn{4}{|c|}{ - kg/planta } & $\%$ & \\
\hline $1962-63$ & 0,352 & 0,348 & 0,347 & 0,342 & - & - \\
\hline $1964-65$ & 0,583 & 0,694 & 0,574 & 0,484 & 35 & $2,11 \mathrm{~ns}$ \\
\hline $1966-67$ & 0,740 & 0,905 & 0,632 & 0,837 & 18 & $8,33^{* *}$ \\
\hline $1968-69$ & 0,547 & 0,596 & 0,474 & 0,649 & 27 & $2,28 \mathrm{~ns}$ \\
\hline $1970-71$ & 0,814 & 0,860 & 0,630 & 0,878 & 18 & $8,44^{* *}$ \\
\hline $1966-71$ & 0,700 & 0,787 & 0,579 & 0,788 & 20 & $6,26 * *$ \\
\hline
\end{tabular}

**: Significativo a $1 \%$ de probabilidade. ns: Não significativo. 
gênio nos biênios 1962-63, 1964-65, 1966-67, 1968-69, 1970-71 e no período 1966-71, compreendendo os três últimos biênios citados, e os quadros 7 e 8 apresentam as médias das produçסes por doses e parcelamentos de nitrogênio nos mesmos períodos citados a partir do biênio 1966-67.

QUADRO 7 - Doses de nitrogênio na adubação do cafeeiro: média da produção acumulada de café beneficiado, em Podzolico Vermelho-Amarelo orto. Cada dado é média dos tratamentos com as quatro fontes e os parcelamentos 2,3 e 4 acumulados durante os periodos indicados

\begin{tabular}{|c|c|c|c|c|c|c|c|}
\hline \multirow{2}{*}{ Período } & \multicolumn{5}{|c|}{ Doses de $N(\mathrm{~kg} / \mathrm{ha})$} & \multirow{2}{*}{$\mathrm{CV}$} & \multirow{2}{*}{$\mathrm{F}$} \\
\hline & 0 & 75 & 150 & 225 & 300 & & \\
\hline & \multicolumn{5}{|c|}{ - $\mathrm{kg} / \mathrm{planta}$} & $\%$ & \\
\hline $1966-67$ & 0,130 & 0,454 & 0,761 & 0,940 & 0,958 & 18 & $32,35^{* *}$ \\
\hline $1968-69$ & 0,120 & 0,423 & 0,635 & 0,585 & 0,620 & 29 & $4,32^{*}$ \\
\hline $1970-71$ & 0,173 & 0,638 & 0,854 & 0,794 & 0,897 & 18 & $7,91 * *$ \\
\hline $1966-71$ & 0,144 & 0,496 & 0,731 & 0,761 & 0,825 & 20 & $13,06^{* *}$ \\
\hline
\end{tabular}

* : Significativo a $5 \%$ de probabilidade. ** : Significativo a $1 \%$ de probabilidade.

QUADRO 8 - Parcelamento e doses de nitrogênio na adubação do cafeeiro: média da produção acumulada de café beneficiado em Podzólico Vermelho-Amarelo orto. Cada dado é média dos tratamentos com as doses 1,2 e 3 e as quatro fontes, acumuladas durante os periodos indicados

\begin{tabular}{|c|c|c|c|c|c|c|}
\hline \multirow{2}{*}{ Período } & \multicolumn{4}{|c|}{ Parcelamento } & \multirow{2}{*}{$\mathrm{CV}$} & \multirow{2}{*}{$\mathrm{F}$} \\
\hline & 1 & 2 & 3 & 4 & & \\
\hline & \multicolumn{4}{|c|}{$\longrightarrow \mathrm{kg} / \mathrm{planta} \longrightarrow$} & $\%$ & \\
\hline $1966-67$ & 0,677 & 0,732 & 0,763 & 0,840 & 18 & $1,5 \operatorname{lns}$ \\
\hline $1968-69$ & 0,488 & 0,595 & 0,505 & 0,600 & 27 & $2,10 \mathrm{~ns}$ \\
\hline $1970-71$ & 0,701 & 0,822 & 0,634 & 0,830 & 20 & $4,89 \mathrm{~ns}$ \\
\hline $1966-71$ & 0,622 & 0,718 & 0,647 & 0,776 & 18 & $2,93 \mathrm{~ns}$ \\
\hline
\end{tabular}


As produções referentes a 1962-63 não mostraram nenhuma resposta às adubaçoes nitrogenadas, as quais foram feitas em doses reduzidas e iguais, dado o pequeno porte das plantas novas.

As produçōes de 1964 foram prejudicadas pelas condiçôes climáticas, e as de 1965 mostraram pequenas diferenças para fontes, porém ño estatisticamente significativas.

No biênio 1966-67 foi evidente o efeito das doses crescentes de nitrogênio sobre as produçбes com aumentos correspondentes a 67, 107 e $110 \%$ para as doses de 150,225 e $300 \mathrm{~kg}$ de nitrogênio por hectare, em comparação com as produçōes correspondentes à de $75 \mathrm{~kg}$ de nitrogênio por hectare, cujo aumento alcançou $250 \%$ sobre a produção das parcelas não adubadas com nitrogênio.

As fontes utilizadas mostraram-se significativamente diferentes pelo teste $\mathrm{F}$ a $1 \%$, tendo o sulfato de amônio, o Nitrocálcio e a uréia, produções 43,32 e 17\% maiores que aquelas obtidas com salitre-do-chile. Os parcelamentos não mostraram diferenças significativas, porém uma tendência de aumento com maior número de fracionamentos.

No biênio 1968-69, o efeito das doses sobre as produçðes foi menor que no biênio anterior, com aumentos correspondentes a 50, 38 e 47\% para as doses de 150,225 e $300 \mathrm{~kg}$ de nitrogênio por hectare, em comparação com a de $75 \mathrm{~kg}$ de nitrogênio por hectare, a qual teve aumentos semelhantes ao biênio anterior. $\mathrm{O}$ efeito das diferentes fontes não foi significativo de acordo com o teste $F$, porém o sulfato de amônio, o Nitrocálcio e a uréia superaram o salitre-do-chile em 26,37 e $15 \%$. O fracionamento, também não significativo, pelo teste $F$, mostrou a mesma tendência de aumentos com maior número de parcelamentos das quantidades aplicadas.

No biênio 1970-71, o efeito das doses sobre as produçðes foi significativo, de acordo com o teste $\mathrm{F}$ a $5 \%$, com aumentos de 34,24 e $41 \%$ para as doses de 150,225 e $300 \mathrm{~kg}$ de nitrogênio por hectare, em comparaçâo com as produçðes correspondentes à de $75 \mathrm{~kg}$ de nitrogênio por hectare, a qual teve um aumento de $270 \%$ sobre a produção das parcelas não adubadas com nitrogênio. $\mathrm{O}$ efeito das diferentes fontes foi significativo segundo o teste $\mathrm{F}$ a $1 \%$, mostrando o sulfato de amônio, o Nitrocálcio e a uréia produçð̋es 37 , 39 e $29 \%$ respectivamente maiores que aquelas obtidas com a aplicação do salitre-do-chile. $O$ efeito dos fracionamentos foi significativo segundo o teste F a 5\%, mas não consistente com os resultados até então obtidos, mostrando uma produção menor quando aplicado de uma só vez ern dezembro, ou em três parcelamentos, em outubro, fevereiro e abril. A produção das parcelas com aplicação de nitrogênio em duas vezes, em outubro e fevereiro, foi 
QUADRO 9 - Doses, parcelamento e fontes do nitrogênio na adubação do cafeeiro: média da produção acumulada do café beneficiado, no período 1966-71, em Podzólico Vermelho-Amarelo orto

\begin{tabular}{|c|c|c|c|c|c|}
\hline \multirow{2}{*}{$\begin{array}{c}\text { Doses de } \\
\mathbf{N}\end{array}$} & \multirow{2}{*}{$\begin{array}{c}\text { Parcela- } \\
\text { mento }\end{array}$} & \multicolumn{4}{|c|}{ Fontes de $\mathrm{N}$} \\
\hline & & Uréia & $\begin{array}{l}\text { Sulfato de } \\
\text { amônio }\end{array}$ & $\begin{array}{l}\text { Salitre-do- } \\
\text {-chile }\end{array}$ & $\begin{array}{l}\text { Nitro- } \\
\text { cálcio }\end{array}$ \\
\hline \multicolumn{2}{|l|}{$\mathrm{kg} / \mathrm{ha}$} & \multicolumn{4}{|c|}{ - $\mathrm{kg} /$ planta } \\
\hline 75 & 1 & 0,383 & 0,569 & 0,381 & 0,546 \\
\hline 75 & 2 & 0,379 & 0,713 & 0,595 & 0,347 \\
\hline 75 & 3 & 0,510 & 0,646 & 0,381 & 0,441 \\
\hline 75 & 4 & 0,571 & 0,518 & 0,387 & 0,570 \\
\hline 150 & 1 & 0,585 & 0,730 & 0,480 & 0,904 \\
\hline 150 & 2 & 0,703 & 1,047 & 0,760 & 0,649 \\
\hline 150 & 3 & 0,647 & 0,599 & 0,546 & 0,758 \\
\hline 150 & 4 & 0,538 & 0,824 & 0,713 & 1,219 \\
\hline 225 & 1 & 0,781 & 0,820 & 0,430 & 0,855 \\
\hline 225 & 2 & 1,045 & 0,625 & 0,736 & 0,883 \\
\hline 225 & 3 & 0,666 & 0,661 & 0,642 & 0,712 \\
\hline 225 & 4 & 0,904 & 0,761 & 0,661 & 0,992 \\
\hline 300 & 2 & 0,750 & 0,932 & 0,475 & 0,855 \\
\hline 300 & 3 & 0,846 & 0,810 & 0,610 & 0,874 \\
\hline 300 & 4 & 0,846 & 1,307 & 0,441 & 1,157 \\
\hline \multicolumn{2}{|c|}{ Sem nitrogênio (média) } & 0,144 & 0,144 & 0,144 & 0,144 \\
\hline
\end{tabular}

$S_{1}=0,136708 . S_{2}=0,121926 . C V_{1}=20 \% . C V_{2}=18 \%$

cerca de $20 \%$ maior que a das primeiras citadas, mas apenas $1 \%$ menor que aquelas das parcelas que receberam quatro parcelamentos em outubro, dezembro, fevereiro e abril.

No período 1966-71, o efeito das doses sobre as produçoes foi significativo segundo o teste $\mathrm{F}$ a $1 \%$ de probabilidade, sendo que os tratamentos com as doses de 150,225 e $300 \mathrm{~kg}$ de nitrogênio por hectare produziram 47,53 e $66 \%$ mais que aqueles com $75 \mathrm{~kg}$ de nitrogênio por hectare, enquan- 
to este produziu $244 \%$ mais que o observado nas parcelas sem adubo nitrogenado. $\mathrm{O}$ efeito das diferentes fontes foi significativo pelo teste $\mathrm{F}$ a $1 \%$ de probabilidade, sendo que as produções das parcelas que receberam sulfato de amônio, Nitrocálcio e uréia foram respectivamente 35,36 e $21 \%$ maiores que aquelas que receberam salitre-do-chile. $O$ efeito dos parcelamentos não foi significativo, tendo havido uma tendência de maiores produçðes quando os adubos foram aplicados em quatro fracionamentos.

\section{CONCLUSOES}

1. As produções obtidas com os aumentos das quantidades de nitrogênio foram crescentes para ambos os solos estudados, tendo havido maiores acréscimos de produçōes para as quantidades mais elevadas de $\mathrm{N}$ no Podzólico Vermelho-Amarelo orto.

2. O sulfato de amônio e o Nitrocálcio mostraram-se significativamente superiores ao salitre-do-chile no Podzólico Vermelho-Amarelo orto. A uréia, apesar de proporcionar maiores produçðes que o salitre-do-chile não se apresentou significativamente superior. Em Latossolo Roxo, as produções seguiram as mesmas tendências, porém as diferenças não foram significativas.

3. A aplicação fracionada das quantidades de nitrogênio não apresentou nenhum efeito no Latossolo Roxo, porém as produçбes obtidas com maior número de fracionamento tiveram tendência para efeitos maiores no Podzólico Vermelho-Amarelo orto.

\section{SUMMARY}

\section{SOURCES AND RATES OF NITROGEN FOR COFFEE TREES, IN TYPES OF SOILS}

Ammonium nitrate limestone (ANL), ammonium sulphate, Chilean nitrate and urea at rates of $75,150,225$ and 300 kilograms of nitrogen per hectare, splitted in 1,2, 3 and 4 applications were used in field experiments with coffee trees, in two soils: in a Red Latosol in Ribeirão Preto and in a Red Yellow OrthoPodzolic in Mococa, State of São Paulo, Brazil In Ribeirão Preto, the experiment was set up in December 1957 and the grain yields were recorded from 1960 to 1969 . In Mococa, the experiment was set up in 1960 and the grain yields were recorded from 1962 to 1971 . The grain yields of coffee increased with the increases in the nitrogen rates applied. The yield responses to high nitrogen rates were greater in the Red Yellow Ortho-Podzolic soil than in the Red Latosol. Ammonium sulphate and ANL resulted in better yields than Chilean nitrate in the Red Yellow Ortho-Podzolic soil. Urea increased coffee yields above those obtained with Chilean nitrate, but the differences were not significant. No significant effects of nitrogen sources were 
observed in the Red Latosol. The practice of splitting the total quantities of nitrogen did not affect the grain yields of coffee in the Red Latosol. In the Red Yellow OrthoPodzolic soil, grain yields were higher when nitrogen was splitted in four applications.

Index terms: coffee; fertilization; fertilizers; nitrogen (N); urea; ammonium sulphate; Chilean nitrate; ammonium nitrate limestone; rates; splitted applications.

\section{REFERÊNCIAS BIBLIOGRÁFICAS}

ABRUÑA, F. \& VICENTE-CHANDLER, J. Effects of six sources of nitrogen on yields, soil acidity, and leaf composition of coffee. Journal Agriculture University of Puerto Rico, 47:41-46, 1963.

CATANI, R. A. \& MORAES, F. R. P. de. Composição química do cafeeiro. Revista de Agricultura, Piracicaba, 33:45-52, 1958.

GALlO, J. R.; BATAGLIA, O. C.; COELHO, F. A. \& TOLEDO, S. V. de. Levantamento do estado nutricional de cafezais de São Paulo, pela análise foliar. I. Solo massapé-salmourão. Bragantia, Campinas, 26:103-108, 1967.

; HIROCE, R.; BATAGLIA, O. C. \& MORAES, F. R. P. de. Levantamento de cafezais do Estado de São Paulo pela análise foliar. II. Solos Podzólicos de Lins e Marília, Latossolo Roxo e Podzólico Vermelho-Amarelo orto. Bragantia, Campinas, 29:237-248, 1970.

de cafeeiro, em relação à adubação química. I. Latossolo Roxo transição para Latossolo Vermelho-Amarelo orto. Bragantia, Campinas, 30:169$178,1971$.

HIROCE, R.; BATAGLIA, O. C.; GALlO, J. R. \& MORAES, F. R. P. de. Teores de nitrogênio em folhas de cafeeiro, em relação à adubação química. II. Solo Podzólico Vermelho-Amarelo orto. Ciência e Cultura, São Paulo, 26(1):64-69, 1974.

; BAUNGARTNER, J. G.; FURLANI, A. M. C. \& MORAES, F. R. $P$. de. Efeito de quatro fontes de adubo nitrogenados nas características químicas do solo e na composição foliar do cafeeiro. Ciência e Cultura, São Paulo, 29(1):67-71, 1977.

LAZZARINI, W.; MORAES, F. R. P. de; MORAES, M. V. de; TOLEDO, S. V. de \& FIGUEIREDO, J. I. Experimentação cafeeira, 1929-1963. Campinas, Instituto Agronômico, 1967. 296p.

LOTT, W. L.; MC LUNG, A. C.; VITA, R. \& GALLO, J. R. Levantamento de cafezais em São Paulo e Paraná pela análise foliar. São Paulo, IBEC, Research Institute, 1961.69p. (Boletim, 26) 
MALAVOLTA, E.; GOMES, F. P. \& COURY, T. Estudos sobre a alimentação mineral do cafeeiro (Coffea arabica L., variedade Bourbon VermeIho) I. Resultados preliminares. Piracicaba, Escola Superior de Agricultura "Luiz de Queiroz", 1958. 18p. (Boletim, 14)

MORAES, F. R. P. de; CERVELLINI, G. S. \& LAZZARINI, W. Adubação química com NPK, B, e Zn em cafeeiros plantados em Latossolo Vermelho-Amarelo orto da Região de Campinas. In: CONGRESSO BRASILEIRO SOBRE PESQUISAS CAFEEIRAS. 2., Poços de Caldas, 1974. Resumos. p.281-282.

; GALLO, J. R.; IGUE, T. \& FIGUEIREDO, J. I. Efeito de três fertilizantes acidificantes sobre a concentração de alumínio e manganês em folhas e raízes de cafeeiros. Bragantia, Campinas, 38(2):7-17, 1979. ; LAZZARINI, W.; TOLEDO, S. V. de; CERVELLINI, G. S. \& FUJIWARA, M. Fontes e doses de nitrogênio na adubação química do cafeeiro. I. Latossolo Roxo transição para Latossolo Vermelho-Amarelo orto. Bragantia, Campinas, 35(6):65-77, 1976. 